\title{
Peer Evaluation of Oral Presentations in Croatia
}

\author{
Mirjana Matea Kovač ${ }^{1} \&$ Nina Sirković ${ }^{1}$ \\ ${ }^{1}$ Faculty of Electrical Engineering, Mechanical Engineering and Naval Architecture, University of Split, Croatia \\ Correspondence: Mirjana Matea Kovač, Faculty of Electrical Engineering, Mechanical Engineering and Naval \\ Architecture, University of Split, Croatia. Tel: 385-21-305-715. E-mail: mirjana.kovac@fesb.hr
}

Received: March 19, 2012 Accepted: April 17, 2012 Online Published: July 1, 2012

doi:10.5539/elt.v5n7p8 URL: http://dx.doi.org/10.5539/elt.v5n7p8

\begin{abstract}
This paper aims to explore student engagement in peer evaluation activities related to giving scientific presentations in English (L2) and to investigate student attitudes towards this form of evaluation in the course Communication skills in Croatian (L1). The participants in this study were first-year students of engineering in Split, Croatia. Peer review grades have shown that the verbal part of delivering oral presentations in English is the most demanding and challenging part in presentations. The results on student attitudes have shown that the students hold positive attitudes towards peer evaluation. Moreover, they claim to have become aware that speech disfluencies (filled and silent pauses, repetitions, false starts, grammatical errors) negatively affect the overall oral performance, pointing out that efforts should be made in order to reduce them, therefore, the course Communication skills is by the vast majority of students regarded as a valuable course in times of increasingly complex communication requirements.
\end{abstract}

Keywords: peer evaluation, communication skills, oral presentations, speech disfluencies, monitoring

\section{Introduction}

The modern labour market imposes a growing demand for highly educated professionals who possess advanced technical knowledge, but who have also acquired good communication skills. Besides professional knowledge, today's engineers must develop other skills including creativity, motivation, decision-making ability, cooperation, and above all, good social skills. Therefore, interdisciplinary study programmes educate experts who gradually obtain all skills necessary to meet the demands of the labour market. Aware of the constant need to develop appropriate communication skills, many American universities introduced and integrated courses in public speaking and communication skills into the existing educational programmes. Also, most of the technical faculties in the Republic of Croatia (Faculty of Electrical Engineering in Zagreb, Faculty of Electrical Engineering, Mechanical Engineering and Naval Architecture in Split and other faculties) introduced the course entitled Communication skills as a mandatory one. Furthermore, renowned accreditation agencies for higher education in the scientific field of technical sciences, such as the Accreditation Board for Engineering and Technology (ABET) and the German Accreditation Agency (ASIIN) propose that the students, besides the engineering skills necessary for the engineering practice, also attain the ability to communicate effectively, that is, they must be able to deliver an effective oral presentation.

The Electrical Engineering curriculum is designed to prepare undergraduate students to become professionals in the field of Electrical Engineering. However, written and oral skills have often been neglected, so today there are many engineers with excellent practical knowledge, but they lack communication skills. Communication skills is an obligatory course in the first semester for first-year students of Electrical Engineering and Computing at the Faculty of Electrical Engineering, Mechanical Engineering and Naval Architecture in Split, Croatia. This course is oriented towards acquiring professional competence in the field of communication skills, that is, according to the requirements of the above mentioned agencies, good presentation skills. Furthermore, the acquired contents from this course have successfully been integrated into the existing English course. Besides concentrating on the specific needs of scientific language, students are expected to develop oral and written communication skills as well.

The aim of this paper is to investigate how students give specific feedback by evaluating oral presentations in English (L2) against established and relevant criteria. In addition, a survey among first-year students at the end of the first semester has been conducted, aiming at exploring student attitudes towards peer evaluation, trying to find out the potential benefits of this form of evaluation in classroom activities, both in the English language (L2) and in the Communication skills course (L1). 


\section{Peer-evaluation}

The issue of peer evaluation has received great attention in recent years. According to Topping (2009: 20-21) peer evaluation can be defined as "an arrangement for learners to consider and specify the level, value, or quality of a product or performance by other equal-status learners". Teachers of English as a Foreign Language often use peer evaluation as a way to increase opportunities for constructive feedback and student interaction. Student participation in the assessment has been advocated on the grounds of the learning benefits as a result of being involved in giving and receiving feedback (Magin and Helmore, 2001). As Magin and Helmore have shown, there is a general agreement on the value of feedback from peer assessment in promoting learning. Kwan and Leung (1996) were of the opinion that the ability to judge the performance of peers critically and objectively is a skill that students should possess when they enter employment. Ballantyne, Hughes and Mylonas (2002) put forward the theory that peer evaluation can provide formative feedback that teachers cannot otherwise provide. In a study on attitudes towards online peer evaluation among L2 university students in Taiwan, Wen and Tsai (2006) found that participants, while generally holding positive attitudes towards peer evaluation, did not regard it as helpful to learning and that males were more likely to have positive attitudes than females. Cheng and Warren (1997) conducted research at a university in Hong Kong and found that while a majority of participants regarded peer evaluation favourably, a minority believed themselves or other students to be excessively biased, viewing their peers as unable to provide fair evaluations or to be unqualified to give evaluations in their L2. However, conversely, Praver, Rouault and Eidswick (2011) claim that peer evaluation in classrooms is a means of improving English skills. It seems that peer evaluations wherein students provide comments are regarded as very useful for English skill development. Also, efforts should be made to reduce the potential for embarrassment and anxiety. These efforts could include evaluation training, as well as establishing ways to provide evaluations anonymously. The results of that study suggest that L2 peer evaluation is an underexplored research subject that could add valuable knowledge for classroom practice. Cheng and Warren (2005) explored the reliability and potential benefits of incorporating peer assessment into English language programmes. Undergraduate engineering students attending a university in Hong Kong were asked to assess the English language proficiency of their peers among other assessment criteria, such as preparation, content, organization and delivery. The authors also compared peer and teacher assessments. The findings suggested that students had a less positive attitude towards assessing their peers' language proficiency, but they did not score their peers' language proficiency very differently from the other assessment criteria.

According to the Quality Improvement Agency for Lifelong Learning (QIA) (2008), peer evaluation is a useful part of assessment for learning, as it enables learners to recognize how to improve their work. Moreover, it has been regarded as an important part of the professional practice in IT. In their view, peer review develops skills in giving and receiving feedback, it builds learners' confidence to present their ideas, it helps learners value interpersonal skills and also increases learners' motivation and persistence. In addition, peer review helps learners see different ways of understanding, including how others sometimes arrive at misconceptions, which in turn greatly strengthens learning.

\section{Research}

\subsection{Participants and Procedure}

The aims of the present study are two-fold. The former aims to explore student engagement in peer evaluation activities in English (L2) whereas the latter tends to investigate student attitudes towards this form of evaluation in the course Communication skills in the native language (L1).

The participants in the first part of the study were 33 native speakers of Croatian, first-year students at the Faculty of Electrical Engineering, Mechanical Engineering and Naval Architecture in Split, Croatia. The students had received 8-9 years of formal English instruction and it was presumed that the participants' instructional background was very similar, since all of them claimed to have received a mixed form-focussed and communicative syllabus as a method of instruction in their primary and secondary school. No test was previously administered to measure their level of proficiency. The English language is taught as an obligatory course which includes two hours of formal instruction a week over a period of three semesters for students of Electrical Engineering and two hours a week during two semesters for students of Computing. The English syllabus includes reading authentic texts, finding key information in the text, translating, acquiring specific technical terminology and syntactic features of technical English.

However, it must be pointed out that the acquired contents from the course Communication skills have been integrated into the existing English course, that is, students are also expected to develop oral communication skills in English. In their Communication skills course, all students were taught the basic principles of giving presentations in accordance with the Pyramid structure (see Figure 1, Baker, 2006) since the pyramid stands for hierarchically designed thinking. Preparation starts with identifying the central message with a clear objective. This leading 
message has a number of key ideas, joined into clusters that support the message. The best way to organize ideas is inductively, by grouping and summarizing them, creating a shape that allows the reader's and listener's mind to understand complex issues in the most natural way. The process consists of two stages: first-stage thinking is gathering information from different sources, whereas second-stage thinking is organizing the information, using the Pyramid principle.

Based on the acquired presentation skills, all 33 students were asked to give a scientific presentation with the primary objective of clearly, concisely, creatively and coherently reviewing the topic. Each presenter had to arrange the thoughts and ideas in a logical way, develop an appropriate style in the language, remember and deliver the ideas with words, non-verbal behaviour and visual cues.

What will be the central idea?

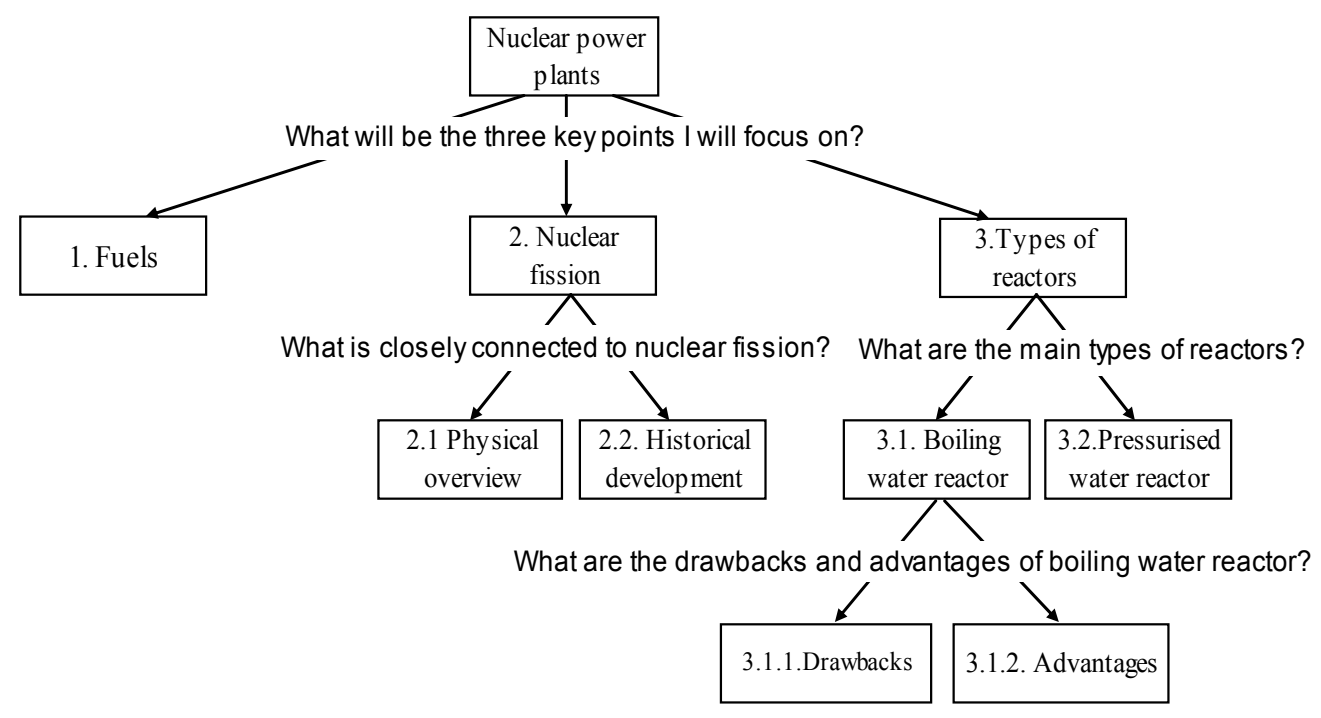

Figure 1. Example of a pyramid

The pyramid brings order into chaos by giving thoughts a clear structure. Each idea is a result of a provoked question. Each key point, sub-point and minor point in the pyramid are answers to the questions shown in the example and this question-answer process results in a pyramid structure. Every idea is a sentence, each idea must summarize the ideas grouped beneath it and each idea within a group is an answer to the question provoked by the summarizing idea. Ideas must be ordered in each group in terms of relevance, chronology or logical reasoning. The ideas need to be relevant and complete, also, summary points must clearly reflect the structure (Barker, 2006). By using the model of a pyramid, the ideas are transferred to slides in the oral presentation.

The students needed to follow the standard structure of a presentation, which included an introduction, two or three key points, a conclusion and inviting questions. Each presentation lasted for six minutes and additional two minutes were allotted for questions that were posed after the presentation. In the teachers' experience, questions are extremely important for creating positive interaction, clearing up misunderstandings, therefore stimulating discussion. Also, questions mirror the level of understanding and the areas of students' special interests. Furthermore, students practice asking morpho-syntactically and semantically well-formed questions, which is for many students a challenging task. Three students from the classroom evaluated the presentations according to different criteria in the form of a questionnaire (Table 1). The questionnaire was created respecting the criteria for grading oral presentations (Surratt, 2006).

Each student gave a presentation and acted as a member of at least three committees. By letting the students participate in the identification of the criteria, they get a better understanding of what is expected, therefore the students and the teacher have defined these criteria together. Being clear about the goals makes a positive contribution to the performance (Locke et al., 1981) and the gap between the teacher's and students' evaluations becomes reduced. Peers and teacher, as two different sources, provide useful data for comparison, helping the student develop an accurate picture of strengths and weaknesses. 
Table 1. Review worksheet for evaluation

\section{a) verbal and vocal delivery}

1. Did the presenter use many disfluencies, such as fillers (mostly "er"), repetitions, false starts, grammatical errors?

Did the presenter use rhetorical questions?

3. Was the pronunciation satisfactory?

4. The speech was:
a) too fast
b) too slow
c) monotonous
d) at moderate pace, adequately loud with a pleasant voice.

5. Did the presenter change intonation?

\section{b) non-verbal communication}

1. Did the presenter follow the rules of effective non-verbal communication (body posture and effective eye contact)?

\section{c) quality of slides}

1. Were the visual aids designed effectively (pie charts, graphs, histograms)?

2. Were the figures and tables of appropriate size, sharpness and colour, properly annotated?

3. Was the used font readable to the audience?

4. Was too much information presented on the slides?

\section{d) questions}

1. Could the speaker answer simple clarification question?

e) organization

1. Was the presenter well-prepared?

2. Did the speaker digress during explanations?

3. Did the topic closely relate to the field of Electrical Engineering?

4. Did the presenter provide sufficient information on the topic?

5. Did the presentation contain all necessary elements, constructed in a logical sequence (key points, minor points, sub points, effective introduction, main body, closing and inviting questions)?

6. Did the presenter follow the KISS (Keep It Short and Simple) principle?

\subsection{The Review Process}

The primary instrument used in this part of the study was a review worksheet presented in Table 1, which was passed to the evaluation committee. The committee graded each aspect of performance with a grade on a scale from one to five ( 1 is the lowest and 5 is the highest score).

\subsection{Survey}

Peer evaluation has also been used as an assessment activity in the Communication skills course (L1). At the end of the first term all first-year Electrical Engineering students (146) were asked to answer a questionnaire in order to find out their attitudes towards this form of evaluation. The questions are presented in Table 2. 
Table 2. Questionnaire on attitudes about peer evaluation

1. When I comment the different levels of performance (verbal, non-verbal, technical and organizational) of my peers, I can perceive errors more clearly and improve some aspects of my future presentation.

2. My comments are useful to my colleagues because they will pay more attention to some future performance by taking corrective measures.

3. I need to acquire theoretical knowledge in order to competently assess my colleague's performance and to decide whether a particular aspect of performance is satisfactory, good, excellent or unsatisfactory.

4. By assessing other presenters I actively participate in class activities and I am forced to pay attention to aspects that are being evaluated.

5. When I evaluate other presenters, I develop the skill of giving and receiving feedback.

6. By evaluating others I acquire the quality standards and evaluation criteria.

7. I develop confidence and I can freely and fearlessly present my comments, explaining what I have observed during the presentation.

8. Peer evaluation is in my opinion useful for learning because it helps me recognize my strengths and weaknesses, I become aware of the aspects which should be paid attention to, consequently I am improving my presentation skills.

9. It is extremely important to know the evaluation criteria and performance standards.

10. I have noticed that my peers mostly show difficulties at the

a) technical level

b) level of speech (use of dialect, poor vocabulary, speech errors,

silent and filled pauses, false starts and restarts etc.)

c) feedback level (no interaction with the audience)

d) non-verbal level (lack of eye contact and inadequate body posture).

11. The acquired knowledge from this course will be of benefit in the future, because almost every topic can be worked out in accordance with the principle of the pyramid used in presentations.

12. Communication skills is a valuable course for students in times of increasingly complex communication requirements.

YES

NO

YES

NO

\section{Results}

From the results presented in Figure 2, it can be seen that the average grade for the verbal performance in the English language (L2) was 3.76. In a survey on the frequency and distribution of speech errors in L2, Kovač (2011) found that morphological errors were dominant in all speech tasks due to a significantly frequent omission of articles. Also, the distribution of different subcategories of lexical errors pointed to a relatively low frequency of unintended L1 switches, indicating that the participants were able to separate the two languages during lexical access. She concluded that the speakers paid very little importance to the use of articles, which can be explained by: a) the influence of the native language (Croatian) which does not have the article system, b) the students' attitude that articles are not important for message understanding and c) formal language teaching does not give adequate importance to article acquisition.

The findings relating to the verbal part of the presentation obtained in this research might suggest the following interpretation. If the students were reminded to pay attention and monitor the grammatical accuracy of their peers, they more frequently noticed the incorrect grammatical usage of tenses, inappropriate pronunciation of words and 
the omission of the definite and indefinite article. Moreover, in their Communication skills course, the students have been taught about the necessity of delivering fluent speech in their native (L1) as well as in the English language (L2), in particular about the usage of silent and filled pauses. The results obtained in a research among engineering students (Kovač and Horga, 2010) showed that the speakers used the unphonemic segment $u h$ very frequently in Croatian. Peer review activities indicate that if the students become aware and monitor the quality of speech, lots of speech errors and other forms of disfluencies do not remain unnoticed.

The average grade for the non-verbal part of presenting showed that the students had acquired the rules for satisfactory body language. The question part and the overall organization were evaluated with the grade 4.2 (Figure 2).

In conclusion, the verbal part of presenting has proven to be the most demanding and the most challenging part of delivering oral presentations.

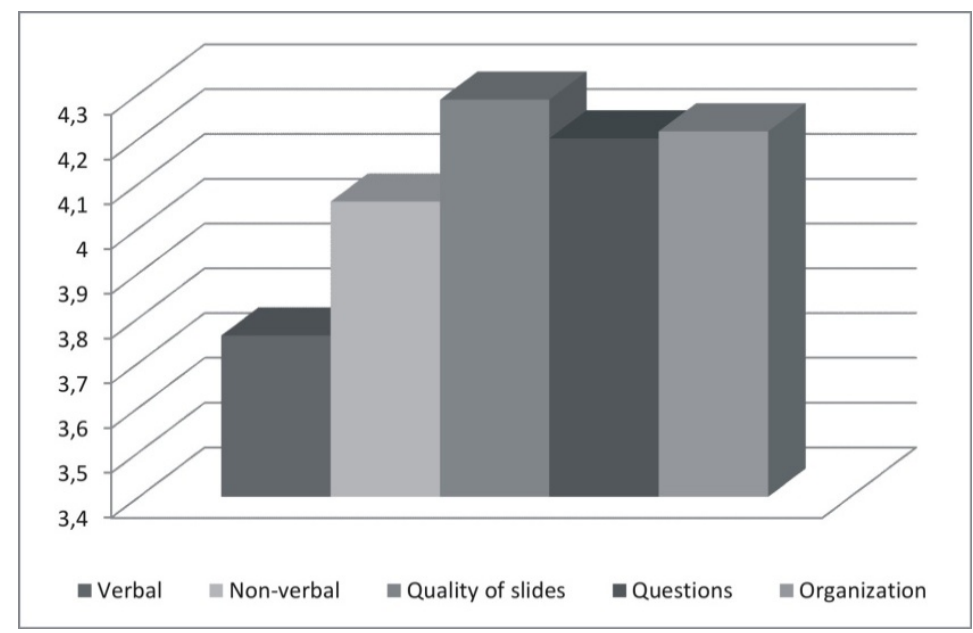

Figure 2. Average grade for different presentation aspects

Figure 3 displays the percentage of students who received a particular grade for the verbal aspect of communication. It is very interesting to notice that none of the 33 presenters were evaluated with grades rated 1 or 2 , whereas $34 \%$ of the presenters received the grade 3 for the verbal performance, $54 \%$ received the grade 4 , and only $12 \%$ of the 33 presenters were graded with 5 , indicating that both the presenters and the evaluation committee paid considerable attention to the various aspects being evaluated. This particularly referred to the excessive use of silent and filled pauses, false starts and restarts, as well as various grammatical errors.

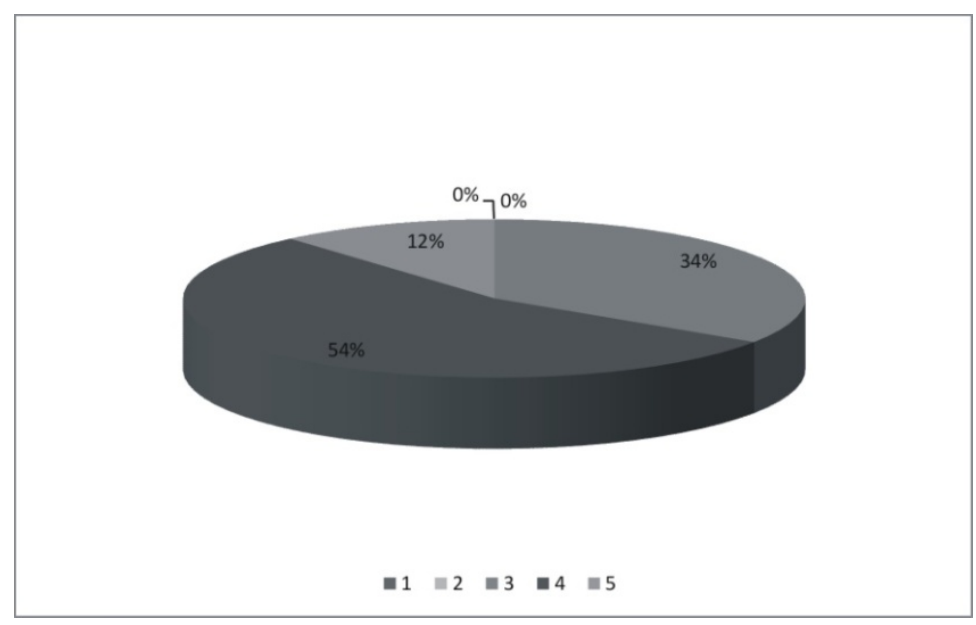

Figure 3. Percentage share of students who received a particular grade for the verbal aspect of communication in L2

However, it must be said that presenting in a foreign language with confidence is a difficult and demanding task. 
Consistent body language, lively speaking and fluent English largely contribute to satisfactory performance. Peer evaluation may have shed light to some aspects which have not fully been taken into consideration, for example, rehearsing out loud in real time which has proven to help the students manage the content, resulting in fluency. It has been noticed that under-rehearsed presenters spent too much time working out what to say, struggling with finding words and expressions, whereas well-rehearsed presenters knew what to say and could improvise according to the demands of the moment.

The results of the second part of this study on attitudes towards peer evaluation are presented in Table 3.

Table 3. Attitudes on peer evaluation

1. When I comment the different levels of performance (verbal, non-verbal, technical and organizational) of my peers, I can perceive errors more clearly and improve some aspects of my future presentation.

2. My comments are useful to my colleagues because they will pay more attention to some future performance by taking corrective measures.

3. I need to acquire theoretical knowledge in order to competently assess my colleague's performance and to decide whether a particular aspect of performance is satisfactory, good, excellent or unsatisfactory.

4. By assessing other presenters I actively participate in class activities and I am forced to pay attention to aspects that are being evaluated.

5. When I evaluate other presenters, I develop the skill of giving and receiving feedback.

YES $88 \%$

NO

$12 \%$

\section{YES}

$75 \%$

NO

$25 \%$

YES $90 \%$

NO

$10 \%$

6. By evaluating others I acquire the quality standards and evaluation criteria.

7. I develop confidence and I can freely and fearlessly present my comments, explaining what I have observed during the presentation.

8. Peer evaluation is in my opinion useful for learning because it helps me recognize my strengths and weaknesses, I become aware of the aspects which should be paid attention $21 \%$ to, consequently I am improving my presentation skills.

\begin{tabular}{llll}
\hline $\begin{array}{l}\text { 9. It is extremely important to know the evaluation criteria } \\
\text { and performance standards. }\end{array}$ & YES & $80 \%$ & $\mathrm{NO}$ \\
\hline
\end{tabular}

10. I have noticed that my peers mostly show difficulties at Circle which levels of performance do you find the
a) technical level
b) level of speech (use of dialect, poor vocabulary, speech errors, silent and filled pauses, false starts and restarts etc.)
a) $30 \%$
b) $80 \%$
c) $20 \%$
c) feedback level (no interaction with the audience)
d) $25 \%$
d) non-verbal level (lack of eye contact and inadequate body

to be the most difficult to master. posture).

11. The acquired knowledge from this course will be of benefit in the future, because almost every topic can be YES $88 \%$ worked out in accordance with the principle of the pyramid $12 \%$ used in presentations.

\begin{tabular}{|c|c|c|}
\hline $\begin{array}{l}\text { 12. Communication skills is a valuable course for students in } \\
\text { times of increasingly complex communication requirements. }\end{array}$ & $\begin{array}{ll}\text { YES } & 82 \% \\
18 \%\end{array}$ & $\mathrm{NO}$ \\
\hline
\end{tabular}

The results of the survey showed that the absolute majority of all 146 students had positive attitudes towards peer evaluation. The majority of participants (88\%) think that peer evaluation, in other words, commenting about different levels of performance (verbal, non-verbal, technical and organizational) can help perceive errors more 
clearly and consequently improve some aspects of future presentations. Also, $90 \%$ shared the opinion that it was important to acquire theoretical knowledge in order to competently assess others, and to decide whether a particular aspect of performance was satisfactory, good, excellent or unsatisfactory. Active classroom participation and monitoring were other positive outcomes for $89 \%$ of the participants. $90 \%$ considered peer review as a means for developing the skills of giving and receiving feedback. Moreover, $92 \%$ thought that peer review helped learners understand quality standards and assessment criteria; whereas $92 \%$ believed that this form of evaluation changed the attitude towards speaking by developing self-esteem and confidence.

The findings supported the results of the researches conducted among engineering students, showing that the students tended to show most difficulties at the level of speech production, independently of the language in use, either Croatian or English. $80 \%$ of the participants thought that the students struggled with poor vocabulary, speech errors, the excessive use of silent and filled pauses, false starts and restarts, whereas the technical level of performance was in the opinion of $30 \%$ of the participants a less difficult part of presenting. The obtained results point to the assumption that the students are aware that speech disfluencies negatively affect the overall oral performance and that efforts should be made in order to reduce them. Therefore the course Communication skills was by the vast majority of participants $(82 \%)$ regarded as a valuable course in times of increasingly complex communication requirements. In addition, $88 \%$ thought that the acquired knowledge from this course would be of benefit in the future, because almost every topic can be worked out in accordance with the pyramid principle used in presentations.

The interpretations of the obtained results seem to point to the conclusion that peer evaluation can play a useful role in improving fluency in the native language (L1) by raising awareness about the necessity of speech monitoring. Also, peer evaluation in foreign language teaching can result in changing the students' attitude towards speaking, which contributes to an overall positive attitude to learning.

\section{Conclusion}

Peer assessment activities have been embedded in the courses entitled Communication skills and English language, influencing student learning in a positive way. If the students are reminded to pay attention and monitor the grammatical accuracy of their peers, they more frequently notice incorrect grammatical usage of tenses, inappropriate pronunciation of words and the omission of the definite and indefinite article. Consequently, the students become aware of the necessity of delivering fluent speech in the native (L1) as well as in the English language (L2). The results of the survey have shown that the students had positive attitudes towards peer evaluation. Commenting different levels of performance can help perceive errors more clearly, also, it is important to acquire theoretical knowledge in order to competently assess others. This form of evaluation ensures active classroom participation and the development of monitoring skills. Peer review is considered as a means for developing the skills of giving and receiving feedback. Moreover, peer evaluation lessens speaking anxiety and boosts self-confidence. The obtained results point to the assumption that the students are aware that speech disfluencies negatively affect the overall oral performance and that efforts should be made in order to reduce them, therefore, the course Communication skills is by the vast majority of participants regarded as a valuable course in times of increasingly complex communication requirements. In conclusion, peer assessment can be a powerful tool to increase learning by positively changing the attitude towards speaking, making the classes more dynamic and interesting, both for the teacher and the students.

\section{References}

Ballantyne, R., Hughes, K., \& Mylonas, A. (2002). Developing procedures for implementing peer assessment in large classes using an action research process. Assessment and Evaluation in Higher Education, 27, 427-441. http://dx.doi.org/10.1080/0260293022000009302

Barker, A. (2006). Improve your communication skills. London and Philadelphia: Kogan Page Publishers.

Cheng, W., \& Warren, M. (1997). Having second thoughts: student perceptions before and after a peer assessment exercise. Studies in Higher Education, 22, 233-239. http://dx.doi.org/10.1080/03075079712331381064

Cheng, W., \& Warren, M. (2005). Peer assessment of language proficiency. Language Testing, 22, 93-121, http://dx.doi.org/10.1191/02655322051t298oa

Kovač, Mirjana Matea, \& Horga, D. (2010). Govorne pogreške studenata tehničkih studija. Slavistična revija, 58(4), 419-443.

Kovač, Mirjana Matea, \& Sirković, Nina. (2010). Developing oral and written communication skills. Strani jezici, 39(1-2), 89-103. 
Kovač, Mirjana Matea. (2011). Speech Errors in English as Foreign Language: A Case Study of Engineering Students in Croatia. English Language and Literature Studies, 1(1), 20-39. Canadian Center of Science and Education. http://dx.doi.org/10.5539/ells.v1n1p20

Kwan, K., \& Leung, R. (1996). Tutor versus peer group assessment of student performance in a simulation training exercise. Assessment and Evaluation in Higher Education, 21(3), 205-214. http://dx.doi.org/10.1080/0260293960210301

Locke, E., Shaw, K., Saari, L., \& Latham, G. (1981). Goal setting and task performance: 1969-1980. Psychological Bulletin, 90(1), 125-152. http://dx.doi.org/10.1037/0033-2909.90.1.125

Magin, D., \& Helmore P. (2001). Peer and Teacher Assessments of Oral Presentation Skills: how reliable are they? Studies in Higher Education, 26(3), 287-298. http://dx.doi.org/10.1080/03075070120076264

Praver, M., Rouault, G., \& Eidswick, J. (2011). Attitudes and Affect towards Peer Evaluation in EFL Reading Circles. The Reading Matrix, 11(2), 89- 99.

Quality Improvement Agency for Lifelong Learning (QIA). (2008). Teaching and Learning Programme.

Štambuk, A. (2002). English in Electrical Engineering and Computing. Split: FESB.

Surrat, C. K. (2006). Instructional design and assessment - Creation of a Graduate Oral/Written Communication Skills Course. American Journal of Pharmaceutical Education, 70(1), 1-8. http://dx.doi.org/10.5688/aj700105

Topping, K. J. (2009). Peer assessment. Theory into Practice, 48, 20-27. http://dx.doi.org/10.1080/00405840802577569

Wen, M. L., \& Tsai, C. (2006). University students' perceptions of and attitudes towards (online) peer assessment. Higher Education, 51, 27-44. http://dx.doi.org/10.1007/s10734-004-6375-8 